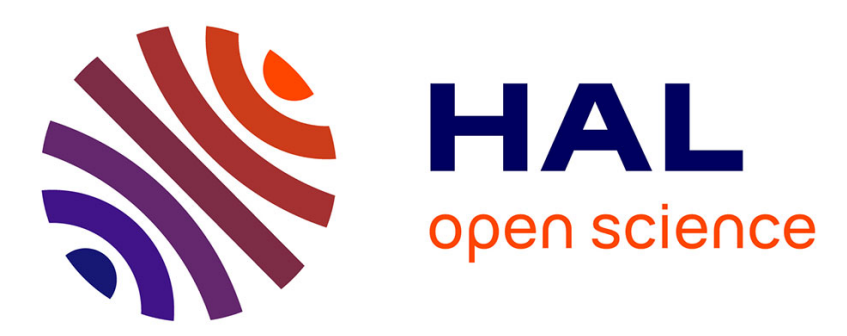

\title{
Refined RGB Strategy for the Synthesis of Polymer-Based Full Organic Luminescent Nanotubes with Broad Emission Bands
}

Ravil Petrov, Matthieu Loumaigne, Régis Barille, Pierre Frère

\section{- To cite this version:}

Ravil Petrov, Matthieu Loumaigne, Régis Barille, Pierre Frère. Refined RGB Strategy for the Synthesis of Polymer-Based Full Organic Luminescent Nanotubes with Broad Emission Bands. ChemPhotoChem, In press, 10.1002/cptc.202000150 . hal-02928310

\author{
HAL Id: hal-02928310 \\ https://hal.science/hal-02928310
}

Submitted on 2 Sep 2020

HAL is a multi-disciplinary open access archive for the deposit and dissemination of scientific research documents, whether they are published or not. The documents may come from teaching and research institutions in France or abroad, or from public or private research centers.
L'archive ouverte pluridisciplinaire $\mathbf{H A L}$, est destinée au dépôt et à la diffusion de documents scientifiques de niveau recherche, publiés ou non, émanant des établissements d'enseignement et de recherche français ou étrangers, des laboratoires publics ou privés. 
archives-ouvertes

\section{Refined RGB Strategy for the Synthesis of Polymer-Based Full Organic Luminescent Nanotubes with Broad Emission Bands}

Ravil Petrov, Matthieu Loumaigne, Régis Barille, Pierre Frère

\section{- To cite this version:}

Ravil Petrov, Matthieu Loumaigne, Régis Barille, Pierre Frère. Refined RGB Strategy for the Synthesis of Polymer-Based Full Organic Luminescent Nanotubes with Broad Emission Bands. ChemPhotoChem, Wiley, 2020, 10.1002/cptc.202000150 . hal-02928310

\section{HAL Id: hal-02928310 \\ https://hal.archives-ouvertes.fr/hal-02928310}

Submitted on 2 Sep 2020

HAL is a multi-disciplinary open access archive for the deposit and dissemination of scientific research documents, whether they are published or not. The documents may come from teaching and research institutions in France or abroad, or from public or private research centers.
L'archive ouverte pluridisciplinaire HAL, est destinée au dépôt et à la diffusion de documents scientifiques de niveau recherche, publiés ou non, émanant des établissements d'enseignement et de recherche français ou étrangers, des laboratoires publics ou privés. 


\title{
Refined RGB Strategy for the Synthesis of Polymer-Based Full Organic Luminescent Nanotubes with Broad Emission Bands
}

\author{
Ravil Petrov, ${ }^{[a]}$ Matthieu Loumaigne, ${ }^{[a]}$ Régis Barillé, ${ }^{*[a]}$ and Pierre Frère ${ }^{*[a]}$
}

Light-emitting polymer nanotubes with tailored fluorescence emission bands have been prepared using organic emissive materials based on benzofuran, carbazole, and indolocarbazole scaffolds and investigated with the goal to obtain pure whitelight emission at the nanoscale. The polymer nanostructures were obtained by the anodic aluminium oxide (AAO) template method with PMMA as a transparent polymer matrix and a proficient choice of organic dyes emitting in the blue, green, yellow and red parts of the spectral range. It is demonstrated that combining aqueous dispersions of monochromatic nanotubes is an effective way of generating white light emission due to a simple correlation between the individual color components. Furthermore, it is also possible to target white emission at the nanoscale by adjusting the concentration of the dyes inside single nanotubes in order to obtain optimal color coordinates of $c a .0 .3$ in the CIE chromaticity diagram.

\section{Introduction}

In the last few years, there has been a growing research interest in creating white-light emitting materials for small optoelectronic circuit and display applications. ${ }^{[1-3]}$ However, despite a large variety of versatile strategies proposed to generate white light, the rational design of purely organic materials with a broad and strong emission has not yet become a routine protocol, and their preparation has proven challenging. The laws of physics tell us that accessing a single-molecule based material with broad-band emission is difficult because of the limitation imposed by the Kasha's rule. ${ }^{[4]} \mathrm{A}$ common strategy for generating a white-light emission at the microscopic level is based on the RGB principle. In this context, it is generally agreed that the brightness of the white light hinges on the green light, while the red and blue light simply play a role of adjusting the colour coordinate and colour temperature. ${ }^{[5]}$ In the goal to apply this design principle to nanostructures, one of two pathways can be taken: (i) creating layer-upon-layer assembly to allow the creation of nanoscopic functional multilayer systems; ${ }^{[6-10]}$ (ii) utilizing a multicomponent system.. ${ }^{[11-14]}$ Recently, evidence has been obtained indicating that a broad wavelength emission can be successfully realized the level of a single nanotube. This strategy was based on the spectral selection of two kinds of luminophores in order to minimize the potential charge and energy transfers. However, only a partially organic material was used in that study, such as a redemitting transition metal cluster in combination with a green-

[a] Dr. R. Petrov, Dr. M. Loumaigne, Prof. R. Barillé, Prof. P. Frère MOLTECH-Anjou

Université d'Angers/UMR CNRS 6200

2 Boulevard Lavoisier, 49045 Angers (France)

E-mail: Regis.barille@univ-angers.fr

Pierre.frere@univ-angers.fr

Supporting information for this article is available on the WWW under https://doi.org/10.1002/cptc.202000150 emitting semiconductor polymer from the aryl vinylene series. $^{[15]}$

One-dimensional nanostructures such as wires, rods, belts and tubes have shown great promise as building blocks for bottom-up integrated photonic and optoelectronic devices. ${ }^{[16-22]}$ In comparison to traditional approaches, nanostructures based on organic molecules are able to provide high luminescence efficiencies for a quite low density or concentration of the material. They are straightforward from an engineering point of view, scalable, cheap in processing, and can be fabricated quickly since a controlled self-assembled growth can be implemented. ${ }^{[23-33]}$ Amongst the various possibilities offered by luminescent nano-objects, light-emitting polymer nanotubes have received close attention due to their potential to be operated integrable nanometer-scale light sources. ${ }^{[34]}$ As mentioned above, certain types of light-emitting polymer nanotubes and nanowires have already been reported using luminescent conjugated and dopant-activated polymers as building materials. ${ }^{[15,35-37]}$ Conceptually, both organic and inorganic electroactive materials can be inserted into the tubes to create integrated optical circuits at micro and nanoscales. Given the substantial potential for currently emerging and future nanophotonic applications, the development of practical strategies for the fabrication of light-emitting polymer nanotubes with favorable optical properties, well-defined physical characteristics, high photostability, reproducibility, and broadband emission appears to be of vital importance. In particular, the possibility of developing a methodology that could be used to tune the wavelength of such nano-sources to obtain a pure white emission is highly desirable. ${ }^{[38-41]}$

The presented study was designed to demonstrate the possibility of preparing polymer nanotubes that lead to a uniform broad-band emission through a careful choice of small-molecule organic dyes embedded into a transparent polymer matrix. It was rationalized that the optical properties of the selected dyes would allow absorption of the excitation 
energy at the same wavelength with the subsequent regeneration of emissions at longer wavelengths corresponding to red, green, and blue emissions, thus realizing the RGB concept. Towards this objective, two different approaches have been investigated: (i) mixing appropriate ratios of aqueous dispersions of monochromatic nanotubes, (ii) blending the dyes and varying their composition in the polymer matrix to obtain single-wall nanotubes (SWNT) with a white-light emission.

\section{Results and Discussion}

The targeted dyes giving emissive blue $(\mathrm{B} 1){ }_{1}^{[42]}$ green $(\mathrm{G} 2){ }^{\left[{ }^{[43]}\right.}$ yellow $(\mathrm{Y} 3)^{[44]}$ and red $(\mathrm{R} 4)^{[45]}$ materials in the solid state were selected based on the carbazole (B1, Y3, R4) and benzofuran (G2) units (Figure 1).

\subsection{Spectroscopic Properties}

The UV-visible absorption spectra of the four compounds were obtained at room temperature in a dichloromethane solution (Figure S1 in SI). The optical data are gathered in Table 1. The indolo[3,2-b]carbazole derivative B1 exhibits a strong band at $318 \mathrm{~nm}$ due to a $\pi-\pi^{*}$ electronic transition of the indolocarbazole system and two less intensive bands at 397 and $418 \mathrm{~nm}$, attributed to intramolecular charge transfer (ICT) from the indolocarbazole unit to the external aromatic moieties. ${ }^{[42]}$ The other dissymmetrical systems show intense absorption bands at $391 \mathrm{~nm}$ for $\mathbf{G 2}, 421 \mathrm{~nm}$ for $\mathbf{Y}$, and $481 \mathrm{~nm}$ for R4 all corresponding to the ICT process between the donor and acceptor part of these D-A derivatives. The emissive properties of these dyes were recorded both in solution and in the solid state. Except for B1, which presents an emission band at $400 \mathrm{~nm}$ as a solution in THF, the other derivatives are nonemissive in solution. In the solid state for the powders, all the compounds display emissions upon excitation at $350 \mathrm{~nm}$ (Figure 1). The emission spectra (Figure S2 in SI) present broad bands with the $\lambda_{\text {emis }}$ maxima at $446 \mathrm{~nm}$ for B1 (blue), $525 \mathrm{~nm}$ for G2 (green-yellow), $545 \mathrm{~nm}$ for Y3 (yellow) and $722 \mathrm{~nm}$ for R4 (red). In addition, the emissive properties of the four compounds were examined as dispersed in the thin film of drop-casted PPMA on a glass substrate from the respective DMF solutions of PMMA/dye (30/5 wt. \%, respectively). Upon excitation at $350 \mathrm{~nm}$, the thin films display specific colour emissions (Figure 2) with the wavelength maxima slightly shifted in comparison to the spectra of the powders. Specifically, it was observed an emission in the blue for B1 (460 nm), the green for $\mathbf{G} 2(520 \mathrm{~nm})$, the yellow for Y3 $(565 \mathrm{~nm})$, and the red part of the spectral window for R4 $(705 \mathrm{~nm})$.

\subsection{Preparation and Optical Properties of Monochromatic Nanotubes}

In order to prepare emissive polymer nanotubes, we intended to embed the designed fluorescent dyes into poly(methyl methacrylate) (PMMA) as polymer matrix. We chose PMMA because of its transparency in visible wavelengths, its ability to produce uniform layers, and a suitable glass transition temper-

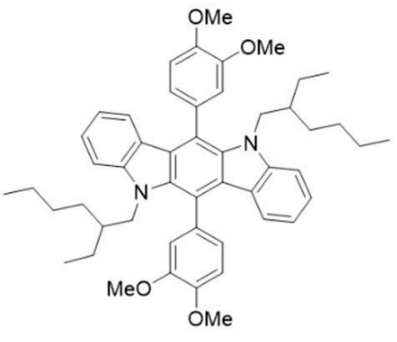

B1

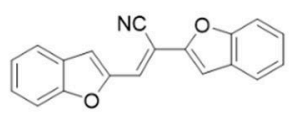

G2
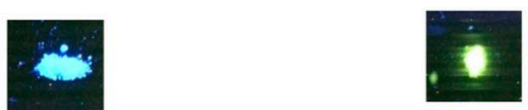

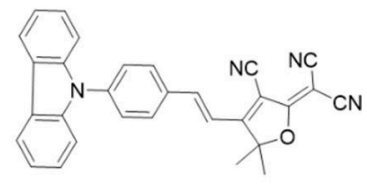

R4
Y3

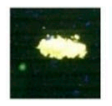

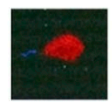

Figure 1. Molecular structures of the selected dyes B1, Y3, R4 and G2 with their respective colour emissions in the solid state under a 350 nm ultra-violet (UV) light excitation.

\begin{tabular}{|c|c|c|c|c|}
\hline Compound & $\begin{array}{l}\text { Absorbance } \\
\text { Solution } \\
\lambda_{\max }[\mathrm{nm}]\end{array}$ & $\lambda_{\text {onset }}[\mathrm{nm}]$ & $\begin{array}{l}\text { Emission } \\
\text { Solid } \\
\lambda_{\max }[\mathrm{nm}]\end{array}$ & $\begin{array}{l}\text { PMMA matrix } \\
\lambda_{\max }[\mathrm{nm}]\end{array}$ \\
\hline B1 & $418,397,338$ & 435 & 446 & 461 \\
\hline $\mathrm{G} 2$ & 391 & 433 & 525 & 527 \\
\hline Y3 & 421 & 472 & 545 & 561 \\
\hline R4 & 481 & 565 & 722 & 706 \\
\hline
\end{tabular}




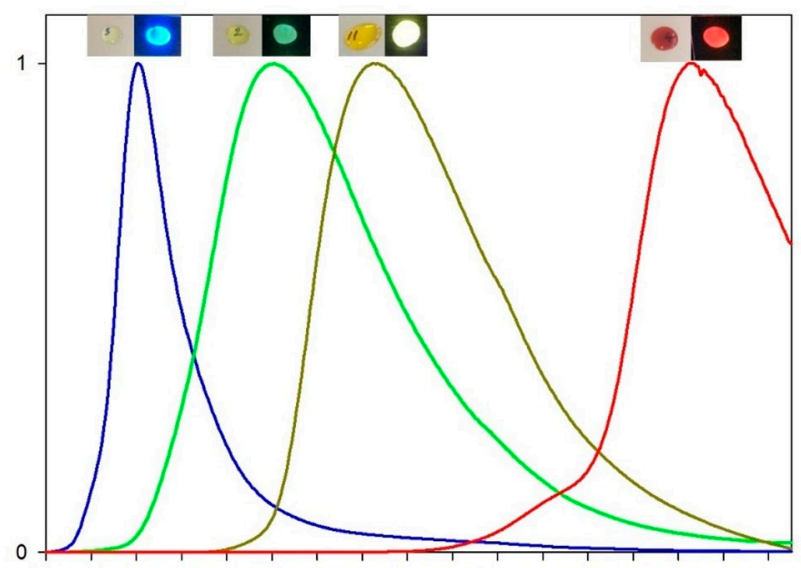

420440460480500520540560580600620640660680700720740

$$
\lambda(\mathrm{nm})
$$

Figure 2. Normalized emission spectra of the selected dyes as dispersed in PMMA films with excitation at $350 \mathrm{~nm}$; B1 (blue), G2 (green), Y3 (darkyellow), R4 (red). The insert photographs showing the colours of the dropcasted samples: (left) in daylight in the polymer/DMF solutions, (right) under UV light after solvent evaporation.

ature for future applications. In our work, the template method in combination with a solution wetting technique was used to prepare the fluorescent polymer nanotubes. This method is well-known for obtaining nanostructures of targeted diameters, length, and polymer compositions. ${ }^{[46-48]}$ In this approach, the template-supported nanotubes were prepared by combining fluorescent dyes with PMMA in an organic solvent (DMF), followed by dropping the obtained solutions onto the hard anodic aluminum oxide (AAO) templates. After filling the nanopores of AAO templates by capillary action, the solvent was removed from the nano-containers by slow evaporation. The free nanotubes were then released from the template by selective etching the template with $35 \%$ phosphoric acid, followed by ultra-sound assisted washings with deionized (DI) water. The coaxial nanotubes were characterized using scanning electron microscopy (SEM), and the results are shown in figure 3a. An average nanotube diameter size of $350 \pm 20 \mathrm{~nm}$ was determined based on the width at half maximum of the diameter size distribution fitted by a Gaussian curve. When SEM measurements were carried out for the nanotubes, the size of the nanotube wall of $5 \mathrm{~nm}$ was determined, with a large distribution in the nanotube length. This is likely a result of the nanotube fabrication process, in which the dissolution of the alumina membrane with phosphoric acid and several sonicatorassisted washings with DI water for removing the phosphoric acid trace could partially break the nanotubes. The nanotube length values were found to be below the membrane thickness, with an average length of $10 \mu \mathrm{m}$.
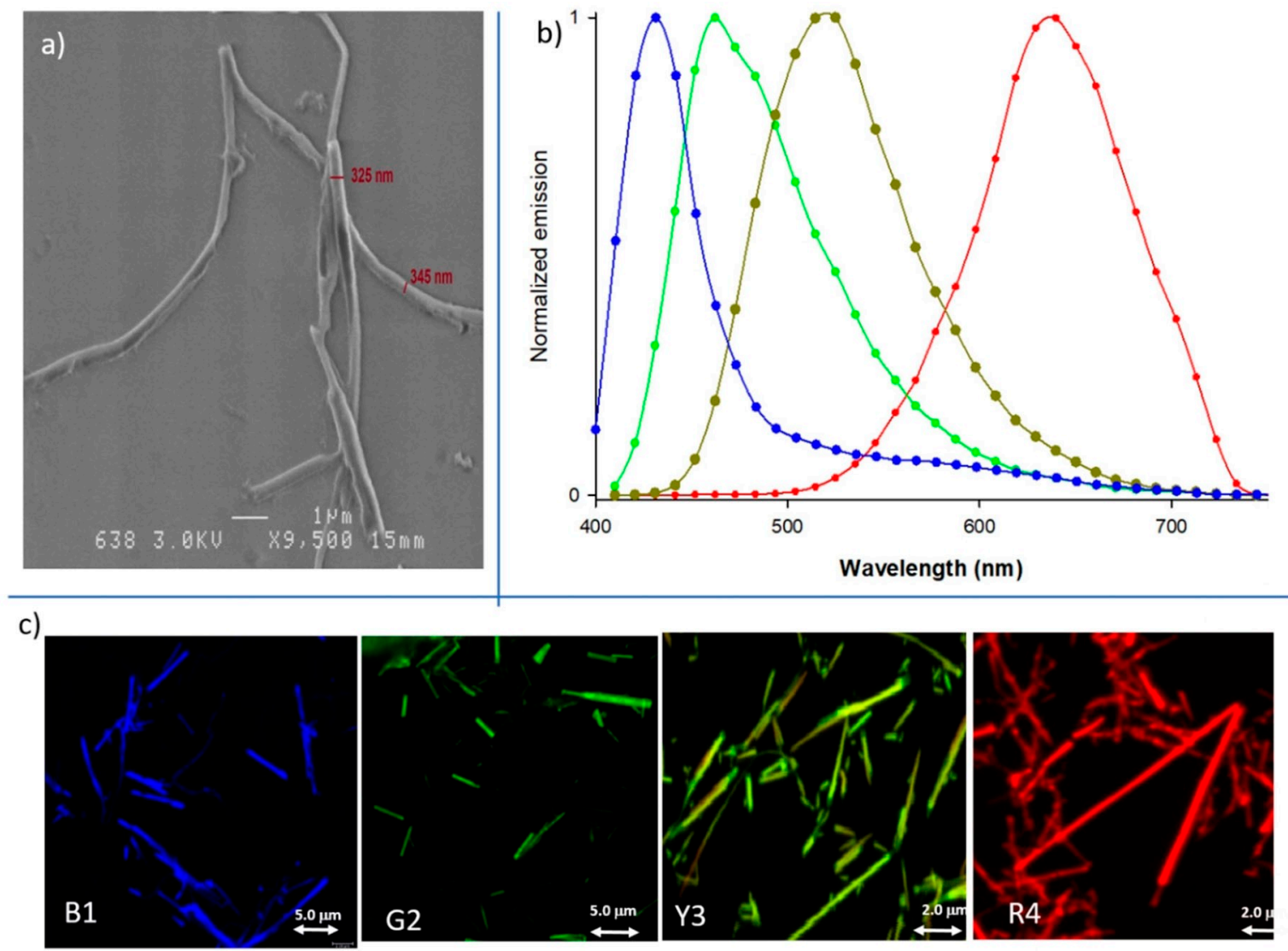

Figure 3. Physical and optical properties of the doped monochromatic nanotubes: a) dispersed PMMA nanotubes on a glass substrate observed with SEM, b) normalized PL emission spectra of individual doped PMMA nanotubes under excitation at 405 nm; B1 (blue line), G2 (green line), Y3 (dark yellow line), and R4 (red line), c) the respective MNTs observed by confocal microscopy. 
For all the four dyes, it was possible to prepare high quality emissive nanotubes with monochromatic color emissions (Figure $3 c$ ). As shown in figure $3 \mathrm{~b}$, the photoluminescence emission spectra under excitation with a laser at $405 \mathrm{~nm}$ for each dye measured on the individual nanotubes present maxima at $431 \mathrm{~nm}$ for B1, $462 \mathrm{~nm}$ for G2, $520 \mathrm{~nm}$ for Y3, and $639 \mathrm{~nm}$ for R4. It should be noted that these maxima are blue-shifted as compared to the ones obtained for the doped PMMA films.

Once the formation of emissive monochromatic nanotubes (MNTs) with specific optical characteristics was validated, we aimed to further explore whether mixtures of these MNTs can be used to obtain a pure white-light emission. We also wanted to explore whether the same effect can be achieved by mixing the dyes in different proportions within the single nanotubes. Consequently, two different approaches were pursued in order to verify the objective in each case.

\subsection{White Light Emission from the Aqueous Dispersions of Mixed Monochromatic Nanotubes}

As mentioned above, we first investigated the possibility to realize the RGB concept by mixing appropriate ratios of MNTs. In formulating the respective samples, it seemed reasonable to use DI water as a suitable dispersing media. In order to obtain the desirable broadband polychromatic emission with the specific colour coordinates, we had to bring the relative intensity of each of the emitted colour to an equal emission level for the same selected excitation wavelength. To this end, three combinations of aqueous dispersions of MNTs were prepared (Table 2) based on the relative emissions of each MNT dispersion. Figure 4 (left) shows the PL (photoluminescence) spectra for each sample of the MNTs before mixing upon excitation at $\lambda_{\text {exc }}=405 \mathrm{~nm}$ as dispersed in water using the same dye concentration of $25 \mathrm{mM}$ and workflow manipulations. The highest emissivity in the yellow part of the spectral range was observed for MNT Y3, and the lowest emissivity was seen in the red spectral range for MNT R1. The respective UV measurements for the mixed samples revealed that the combination $B$ provided the most balanced ratio of $\mathrm{R}: \mathrm{G}: \mathrm{B}$ colours. Compared to the composition $B$, the red region was emphasized better in the composition $A$, while the blue region was more exhibited in the composition C.

The results of the PL measurements (Figure 4 right) for the compositions A, B and C upon light excitation at $405 \mathrm{~nm}$ are significant to at least three major aspects of the goal of colour management. First, they indicate broad emissions ranging from $400 \mathrm{~nm}$ to $750 \mathrm{~nm}$, which is the hallmark feature of a white light emission. In these spectra, emissions of the individual components can be clearly discerned, suggesting no significant energy transfer by this approach. Second, colour adjustments were implemented by a ratiometric method in all three cases, signifying the tunability of this approach through a simple linear correlation between the emissions of monochromatic components and the respective compositions. This result provides an additional evidence for the rational approach implemented to manage the light emission. Third, the high quality of white light emission from these compositions is

\begin{tabular}{|c|c|c|c|c|}
\hline Combination. & $\begin{array}{l}\text { Relative } \\
\text { MN B1 }\end{array}$ & MN G2 & MN Y3 & MN R4 \\
\hline$A$ & 25 & 15 & 10 & 50 \\
\hline B & 30 & 18 & 9 & 43 \\
\hline C & 33 & 23 & 7 & 37 \\
\hline
\end{tabular}
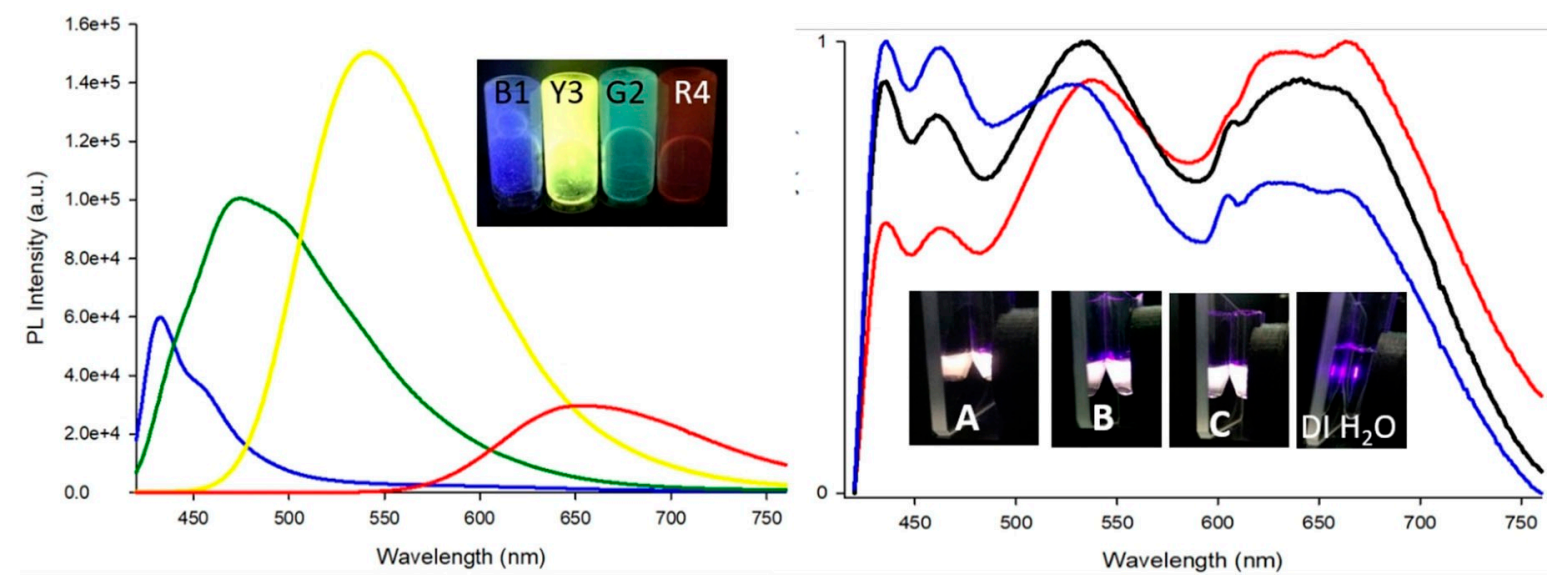

Figure 4. Optical characterization of MNTs and their mixtures as dispersions in DI water. Left: Emission intensity of aqueous dispersions of MNs (dye conc. of $25 \mathrm{mM}$ ) upon excitation at $405 \mathrm{~nm}$ for B1 (blue), G2 (green), Y3 (yellow), and R2 (red); the insert photograph showing the color emissions of the respective MNT dispersed in water under excitation at $350 \mathrm{~nm}$. Right: Normalized photoluminescent spectra for the combinations of monochromatic nanotubes in DI water upon excitation at $405 \mathrm{~nm}$ for comb. A (red), B (black), and C (blue). Inset photographs showing the quality of white light emission for each combination (A, B, and C) vs. a control sample with DI water. 
readily apparent on the photographs in the figure 4 which directly and unequivocally indicate the presence of white-light emitting solutions.

\subsection{Preparation and Optical Properties of Polychromatic Single Nanotubes}

In our second approach, we tested whether it would be possible to prepare SWNTs with a broad emission by simply blending the selected chromophores and varying their proportions in the PMMA matrix. The respective SWNTs were prepared by mixing the dyes in specific molar ratios in 5\% wt PMMA in DMF and following essentially the same workflow protocol as described above. The resultant polychromatic nanotubes (PNT) were characterized by the confocal fluorescence microscopy in a similar fashion. We first attempted to mix dyes Y3 and R4 in an equimolar ratio. A photograph of the corresponding nanotubes together with the respective PL spectrum are presented in the upper portion of the figure 5 . In this case, we observed PNTs with a homogenous emission and the PL spectrum exhibiting one major band centered at $619 \mathrm{~nm}$ with a full-width at half maximum (FWHM) of $96154 \mathrm{~cm}^{-1}$. The corresponding CIE coordinates, $x=0.59$ and $y=0.4$, were found to be located in the red-orange region. In comparison to the monochromatic MNTs, mixing of the two dyes resulted in a slightly enlarged emission band that presented no direct correlation with the individual components from each dye. Thus, the higher energy emission of the yellow dye Y3 appears to be engulfed almost completely, apparently as a contribution to the increase in red emission. This result highlights the extent of energy transfers possible between dyes R4 and Y3. In our next attempt, the four dyes $B 1 / G 2 / Y 3 / R 4$ were mixed in a 40/10/10/5 ratio. $A$ fluorescence microscopy picture of the PNTs obtained together with the resultant PL spectrum are presented at the bottom of the figure 5. Similarly, emission of the resultant PNTs was found to be homogenous with a large band presenting a maximum at $493 \mathrm{~nm}$, a shoulder around $550 \mathrm{~nm}$, and the foot of the band reaching $730 \mathrm{~nm}$, which altogether corresponded to the CIE coordinates of $x=0.27$ and $y=0.39$ (blue-green).

Considering the results above, we sought to explore whether a pure white-light emission can be achieved by mixing three dyes, B1 and R4 with G2 or Y3. Two examples towards this objective are presented in the figure 6 . Indeed, the $\mathrm{CIE}$ coordinates of the PNTs obtained by mixing dyes B1/G2/R4 in a molar ratio of $8 / 4 / 1$ presented in the first example were found to be located in the white light region of the CIE coordinates with $x=0.31$ and $y=0.36$ (Figure 6 top). This result was concluded from the respective PL spectrum showing a broad emission from 400 to $700 \mathrm{~nm}$ with two maxima bands centered at 440 and $555 \mathrm{~nm}$, indicating that in this mixture the green emitter G2 is affected by the energy transfer. In the second example, where dyes B1/Y3/R4 were mixed in a molar ratio of $5 / 1 / 1$, the resultant PNTs also presented a white emission with a good quality ranging from 400 to $720 \mathrm{~nm}$ with the corresponding CIE coordinates $x=0.32$ and $y=0.37$ (Fig-
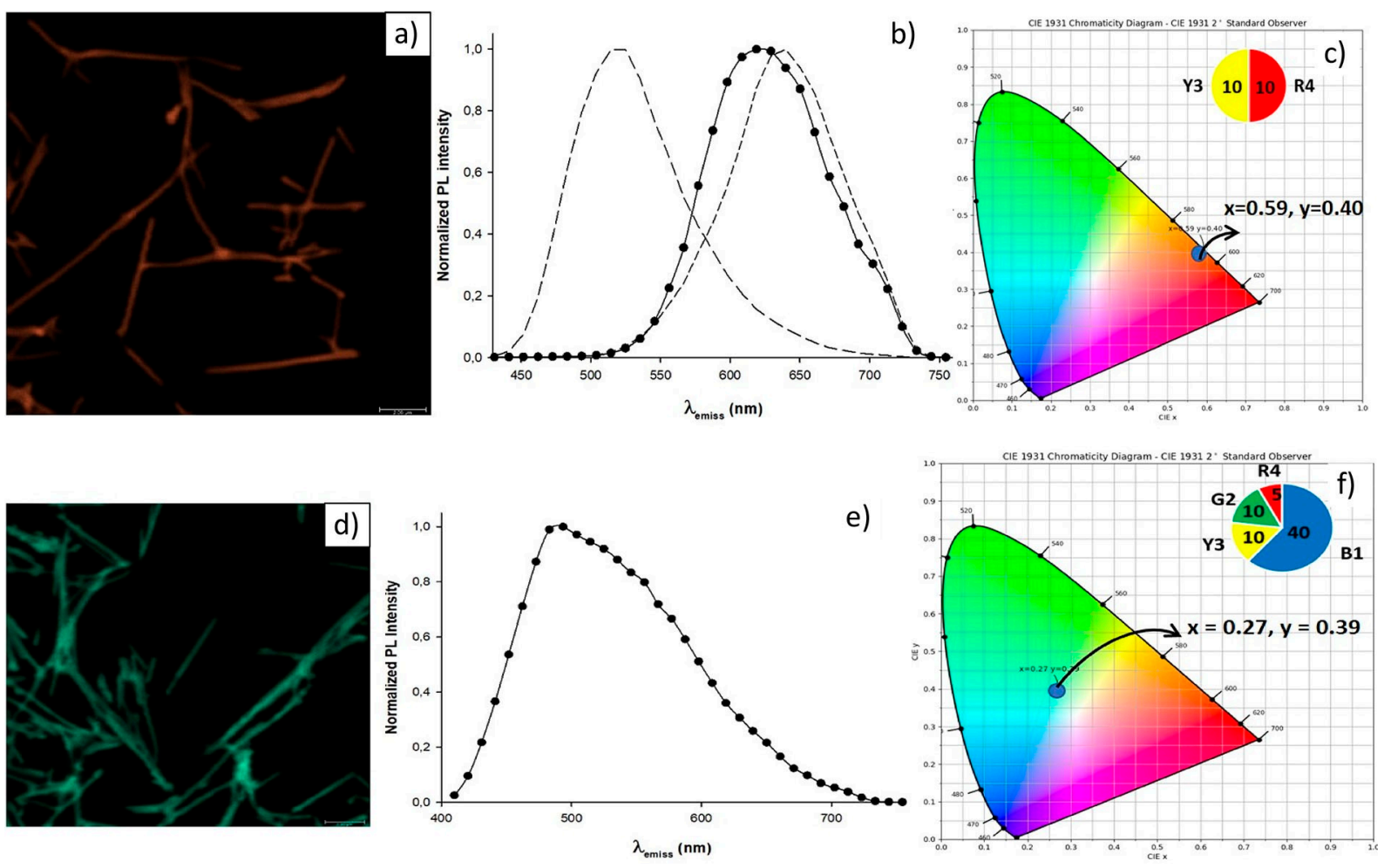

Figure 5. Optical characterization of polychromatic nanotubes obtained by mixing two and four dyes: a, d) confocal microscopy images of the PNTs obtained by mixing Y3/R4 (molar ratio $1: 1$ ) and B1/G2/Y3/R4 (molar ratio 40/10/10/5); b,e) the respective PL spectra; $c$, $\mathrm{f}$ ) CIE chromaticity diagrams showing coordinates of PNTs with $\mathrm{x}=0.59$ and $\mathrm{y}=0.4$ for the first and $\mathrm{x}=0.32$ and $\mathrm{y}=0.37$ for the second combination, respectively. 

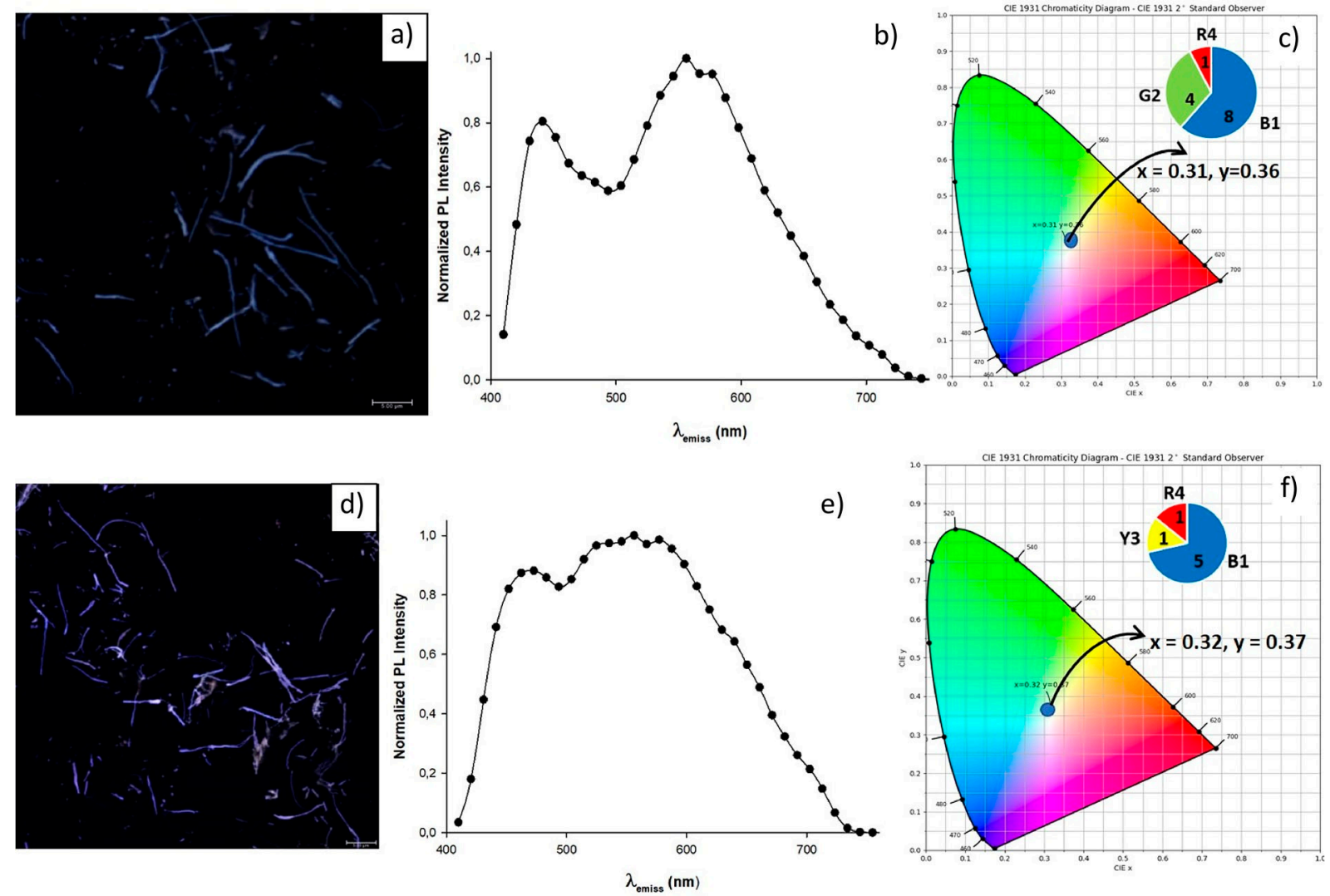

Figure 6. Optical characterization of PNTs obtained by mixing three dyes B1 and R4 with G2 or Y3: a, d) confocal microscopy images of the nanotubes obtained by mixing B1/G2/R4 (mol. ratio 8/4/1) and B1/Y3/R4 (mol. ratio 5/1/1); b,e) the respective PL spectra; $\mathrm{C}$, $\mathrm{f}$ CIE chromaticity diagrams showing coordinates for the first $(x=0.31$ and $y=0.36)$ and the second $(x=0.32$ and $y=0.37)$ dye combinations, respectively.

ure 6 bottom). In the two images by confocal microscopy we observed that the average nanotube diameter and length are similar corresponding to the pore diameter and thickness of the alumina membrane. The small variations in intensities are due to local inhomogeneity and superposition of the nanotubes. In both cases the points corresponding to the Figure $6 a$ and $6 \mathrm{~b}$ in the CIE color space are closed to the white light reference value $(x=0.33, y=0.33)$.

\section{Conclusion}

In the work that is reported herein, we sought to gain insights into the viability of a RGB strategy for producing nanotubes with a broad-band fluorescent emission through a careful choice of small molecule organic dyes embedded into the polymer matrix. Towards this goal, we prepared fluorescent PMMA-based nanotubes with a wall thickness of $5 \mathrm{~nm}$ and a diameter of $350 \pm 20 \mathrm{~nm}$. The transparent host polymer used for the fabrication of these nanotubes was doped with a sufficient concentration of fluorescent guest molecules to ensure the formation of highly emissive aggregates after solvent evaporation. The dyes based on carbazole (B1, Y3, R4) and benzofuran (G2) units allowed us to prepare organic nanomaterials with the specific blue (B1), green (G2), yellow (Y3), and red (R4) emissions in the solid state. We have shown that the optical properties of these dyes permit absorption of the excitation energy at the same wavelength $\lambda=405 \mathrm{~nm}$ with the subsequent regeneration of emissions at longer wavelengths corresponding to red, green, and blue emission ranges, which is necessary for realizing the RGB concept. We showed the key factors affecting the photophysical properties of resultant nanotubes by determining the best structural composition for obtaining white light at the microscopic and macroscopic levels, and formulating simple strategies to open up new ways for realizing white light in 1-D nanostructures.

\section{Supporting Information}

Details concerning the synthesis and characterization of the dyes and the preparation of the nanotubes can be found in the Supporting information

\section{Acknowledgements}

We would like to thank Région Pays de la Loire and RFI LUMOMAT for the postdoc grant for R. Petrov. 


\section{Conflict of Interest}

The authors declare no conflict of interest.

Keywords: chromophores - nanotubes $\cdot$ single-wall polymer nanotubes $\cdot$ white light emission

[1] M. C. Gather, A. Köhnen, K. Meerholz, Adv. Mater. 2011, 23, 233-248.

[2] G. M. Farinola, R. Ragni, Chem. Soc. Rev. 2011, 40, 3467-3482.

[3] C. Tang, X.-D. Liu, F. Liu, X.-L. Wang, H. Xu, W. Huang, Macromol. Chem. Phys. 2013, 214, 314-342.

[4] Z. Chen, C.-L. Ho, L. Wang, W.-Y. Wong, Adv. Mater. 2020, 32, 1903269.

[5] W.-C. Chen, C.-S. Lee, Q.-X. Tong, J. Mater. Chem. C 2015, 3, $10957-$ 10963.

[6] K. Ariga, Y. Yamauchi, G. Rydzek, Q. Ji, Y. Yonamine, K. C.-W. Wu, J. P. Hill, Chem. Lett. 2014, 43, 36-68.

[7] B. W. D'Andrade, M. E. Thompson, S. R. Forrest, Adv. Mater. 2002, 14, 147-151.

[8] I. O. Ozel, T. Ozel, H. V. Demir, D. Tuncel, Opt. Express 2010, 18, 670-684.

[9] C. Foucher, B. Guilhabert, A. L. Kanibolotsky, P. J. Skabara, N. Laurand, M. D. Dawson, Opt. Express 2016, 24, 2273-2280.

[10] M. Börgardts, T. J. J. Müller, Beilstein J. Org. Chem. 2017, 13, 768-778.

[11] W. Ding, J. Sun, G. Chen, L. Zhou, J. Wang, X. Gu, J. Wan, X. Pu, B. Tang, Z. L. Wang, J. Mater. Chem. C 2019, 7, 10769-10776.

[12] M. M. Alam, S. A. Jenekhe, Macromol. Rapid Commun. 2006, 27, 20532059.

[13] N. Muhamad Sarih, P. Myers, A. Slater, B. Slater, Z. Abdullah, H. A. Tajuddin, S. Maher, Sci. Rep. 2019, 9, 11834.

[14] Y. Liu, M. Nishiura, Y. Wang, Z. Hou, J. Am. Chem. Soc. 2006, 128, 55925593.

[15] A. Garreau, F. Massuyeau, S. Cordier, Y. Molard, E. Gautron, P. Bertoncini, E. Faulques, J. Wery, B. Humbert, A. Bulou, J.-L. Duvail, ACS Nano 2013, 7, 2977-2987.

[16] Y. Xia, P. Yang, Y. Sun, Y. Wu, B. Mayers, B. Gates, Y. Yin, F. Kim, H. Yan, Adv. Mater. 2003, 15, 353-389.

[17] L. Zang, Y. Che, J. S. Moore, Acc. Chem. Res. 2008, 41, 1596-1608.

[18] C.-L. Zhang, S.-H. Yu, Chem. Soc. Rev. 2014, 43, 4423-4448.

[19] H. Hu, S. Wang, X. Feng, M. Pauly, G. Decher, Y. Long, Chem. Soc. Rev. 2020, 49, 509-553.

[20] T. Shimizu, W. Ding, N. Kameta, Chem. Rev. 2020, 120, 2347-2407.

[21] F. S. Kim, G. Ren, S. A. Jenekhe, Chem. Mater. 2011, 23, 682-732.

[22] A. Barhoum, K. Pal, H. Rahier, H. Uludag, I. S. Kim, M. Bechelany, Appl. Mater. Today 2019, 17, 1-35.

[23] Z. M. Hudson, D. J. Lunn, M. A. Winnik, I. Manners, Nat. Commun. 2014, $5,3372$.

[24] J. Brewer, M. Schiek, A. Lützen, K. Al-Shamery, H. G. Rubahn, Nano Lett. 2006, 6, 2656-2659.
[25] F. Gu, H. Yu, P. Wang, Z. Yang, L. Tong, ACS Nano 2010, 4, 5332-5338.

[26] M. Zhang, X. Zhao, G. Zhang, G. Wei, Z. Su, J. Mater. Chem. B 2017, 5, 1699-1711.

[27] X. Liu, Y. Li, Dalton Trans. 2009, 6447-6457.

[28] X. Xin, M. Zhang, J. Zhao, C. Han, X. Liu, Z. Xiao, L. Zhang, B. Xu, W. Guo, R. Wang, D. Sun, J. Mater. Chem. C 2017, 5, 601-606.

[29] K. H. Cheng, Y. Zhong, B. Y. Xie, Y. Q. Dong, Y. Hong, J. Z. Sun, B. Z. Tang, K. S. Wong, J. Phys. Chem. C 2008, 112, 17507-17511.

[30] B.-K. An, S. H. Gihm, J. W. Chung, C. R. Park, S.-K. Kwon, S. Y. Park, J. Am Chem. Soc. 2009, 131, 3950-3957.

[31] E. R. Sauvé, C. M. Tonge, Z. M. Hudson, J. Am. Chem. Soc. 2019, 141, $16422-16431$.

[32] D. Funes-Hernando, M. Pelaez-Fernandez, D. Winterauer, J. Y. Mevellec, R. Arenal, T. Batten, B. Humbert, J. L. Duvail, Nanoscale 2018, 10, 64376444.

[33] C.-C. Kuo, C.-H. Lin, W.-C. Chen, Macromolecules 2007, 40, 6959-6966.

[34] A. Garreau, J.-L. Duvail, Adv. Opt. Mater. 2014, 2, 1122-1140.

[35] D. H. Park, Y. K. Hong, E. H. Cho, M. S. Kim, D.-C. Kim, J. Bang, J. Kim, J. Joo, ACS Nano 2010, 4, 5155-5162.

[36] P. Lovera, K. Reynolds, G. Redmond, physica status solidi (a) 2009, 206, 2240-2244.

[37] M. Mbarek, A. Garreau, F. Massuyeau, K. Alimi, J. Wéry, E. Faulques, J.-L. Duvail, J. Appl. Polym. Sci. 2019, 136, 48201.

[38] C. Giansante, G. Raffy, C. Schäfer, H. Rahma, M.-T. Kao, A. G. L. Olive, A. Del Guerzo, J. Am. Chem. Soc. 2011, 133, 316-325.

[39] C. Giansante, C. Schäfer, G. Raffy, A. Del Guerzo, J. Phys. Chem. C 2012, 116, 21706-21716.

[40] L. Persano, A. Camposeo, D. Pisignano, Prog. Polym. Sci. 2015, 43, 4895.

[41] S.-S. Lo, L. Yang, C.-P. Chiu, J. Mater. Chem. C 2015, 3, 686-692.

[42] R. A. Irgashev, A. Y. Teslenko, E. F. Zhilina, A. V. Schepochkin, O. S. El'tsov, G. L. Rusinov, V. N. Charushin, Tetrahedron 2014, 70, 4685-4696.

[43] J. Grolleau, R. Petrov, M. Allain, W. G. Skene, P. Frère, ACS Omega 2018, 3, 18542-18552.

[44] Y. Wang, G. Lai, Z. Li, Y. Ma, Y. Shen, C. Wang, Tetrahedron 2015, 71, 2761-2767.

[45] S. Redon, G. Eucat, M. Ipuy, E. Jeanneau, I. Gautier-Luneau, A. Ibanez, C. Andraud, Y. Bretonnière, Dyes Pigm. 2018, 156, 116-132.

[46] C. R. Martin, Acc. Chem. Res. 1995, 28, 61-68.

[47] A. S. Maria Chong, L. K. Tan, J. Deng, H. Gao, Adv. Funct. Mater. 2007, 17, 1629-1635.

[48] J. Martín, J. Maiz, J. Sacristan, C. Mijangos, Polymer 2012, 53, 1149-1166.

Manuscript received: June 17, 2020

Revised manuscript received: August 1, 2020

Accepted manuscript online: August 4, 2020

Version of record online: 


\section{ARTICLES}

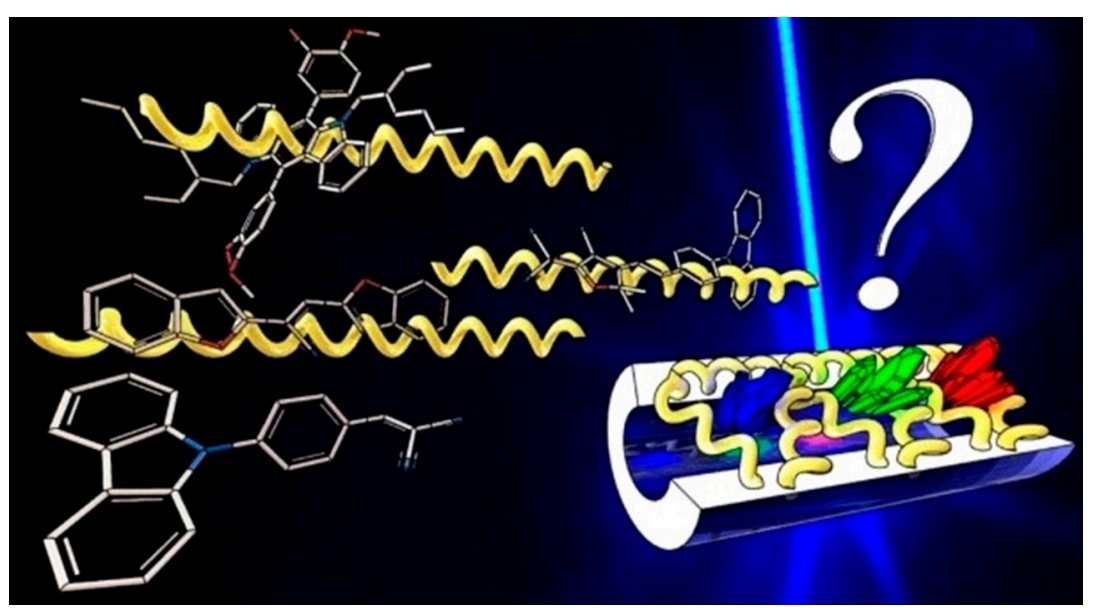

Dr. R. Petrov, Dr. M. Loumaigne, Prof. R. Barillé, Prof. P. Frère*

$1-8$

Refined RGB Strategy for the Synthesis of Polymer-Based Full Organic Luminescent Nanotubes with Broad Emission Bands

Shine bright: The present study describes the preparation of whitelight-emitting polymer nanotubes, obtained by incorporating in a PMMA matrix some organic dyes with specific blue, green, yellow and red emissive properties, either by combining aqueous dispersions of emissive monochromatic nanotubes or by adjusting the concentration of the dyes inside single nanotubes. 